\title{
Oxisteroles: entre la salud y la enfermedad
}

\author{
I. Soto-Rodríguez ${ }^{1}$ - L. E. Ramos Manuel ${ }^{1}$ - C. Barrientos Salcedo ${ }^{1}$
}

\begin{abstract}
RESUMEN
El colesterol es un esteroide de origen animal que cumple numerosas funciones metabólicas, es un precursor de ácidos biliares, de los esteroles fecales, de la vitamina D y de las hormonas esteroideas. Este esteroide es sintetizado en el hígado y otros tejidos, y puede ser absorbido a través de alimentos que se encuentran en nuestra dieta. Tiene una doble ligadura susceptible de oxidarse formando oxiesteroles. No obstante que se encuentran en pequeñas concentraciones son moléculas versátiles porque participan en diversas funciones metabólicas, favorecen algunas patologías ó regulan la expresión de los genes. La intervención de los oxiesteroles en la aterosclerosis es la patología más estudiada, aunque también se ha estudiado su participación en enfermedades neurodegenerativas como el Alzheimer. A partir de la manipulación genética in vivo, así como el uso de simulaciones por ordenadores, se podrá comprender cómo los oxiesteroles gobiernan la señalización celular, modulan la expresión génica, e influyen en nuestra salud o enfermedad.
\end{abstract}

\begin{abstract}
Cholesterol is a steroid of animal origin that meets numerous metabolic functions, is a precursor of bile acids, fecal sterols, vitamin D and steroid hormones. This steroid is synthesized in the liver and other tissues, and can be absorbed through foods that are found in our diet. It has a double ligature susceptible to oxidizing forming oxysterols. Nevertheless they are found in slight concentrations are versatile molecules because they participate in diverse metabolic functions, they advantage some pathologies or they regulate the expression of the genes. The intervention of oxysterols in atherosclerosis is the most studied pathology, although its participation in neurodegenerative diseases such as Alzheimer's has also been studied. So that the novel analytical tools will promote the study of oxysterols health or illness.
\end{abstract}

Palabras Clave: colesterol, esteroide, oxiesteroles, aterosclerosis, Alzheimer.

Keywords: cholesterol, steroid, oxysterols, atherosclerosis, Alzheimer.

$\amalg$ colesterol es un esteroide de origen animal que cumple numerosas funciones metabólicas, es un precursor de ácidos biliares, de los esteroles fecales, de la vitamina D y de las hormonas esteroideas; además posee importantes funciones regulatorias en el metabolismo intracelular de los ácidos grasos, y es junto con los fosfolípidos, un componente esencial de las membranas citoplasmática, nuclear y de los organelos membranosos, favoreciendo su permeabilidad y fluidéz. Este esteroide es sintetizado en el hígado y otros tejidos, pero también puede ser absorbido a través de alimentos que se encuentran en nuestra dieta.

La molécula del colesterol (Fig. 1) posee una doble ligadura por lo que es propenso a sufrir oxidación formándose así los oxiesteroles (Fig. 2) que se diferencian del colesterol por la presencia de grupos polares adicionales que son típicamente hidroxi, ceto, hidroperoxi, epoxi, o restos carbonilo. A pesar de estar presente en concentraciones relativamente pequeñas, se considera que los oxiesteroles son importantes, no sólo porque participan en procesos

1 Facultad de Bioanálisis-Veracruz, Universidad Veracruzana. 
fisiológicos como intermediarios metabólicos, moduladores de lípidos y colesterol, sino porque pueden favorecer ciertas condiciones patológicas, sobre todo las que relacionadas con inflamación crónica. Por esta razón son moléculas muy versátiles, ya que, dependiendo de las condiciones biológicas del individuo, los oxiesteroles podrán actuar de una u otra manera.

Por ejemplo en las células del hígado los oxiesteroles intervienen como reguladores de receptores que, a su vez, controlan el transporte de colesterol, la síntesis de ácidos biliares, y la génesis de grasa en el tejido hepático; pero si se sobre expresan, en este sitio, los procesos de síntesis y transporte de estas moléculas se inhibe, lo que sugiere que la conversión de colesterol a oxiesteroles es un paso importante para la activación de genes en los organismos.

En otros órganos y tejidos los oxiesteroles también son capaces de desencadenar procesos de diferenciación celular, como la formación de las células de Leydig en los testículos, las células del tejido óseo o la producción de glucocorticoides por los adipocitos. Teniendo en cuenta los ejemplos antes mencionados de participación de los oxiesteroles en mecanismos de diferenciación celular, su papel en enfermedades producidas por virus se puede anticipar ya que se ha observado que la activación de ciertos oxiesteroles como el 25-hidroxicolesterol, se expresa de manera prominente en las células del sistema inmunológico, tales como monocitos, macrófagos y células dendríticas, lo que favorece que la replicación viral se suprima.

Por otro lado, la producción y distribución de los oxiesteroles debe ser cuidadosamente controlada, debido a que aumentos anormales de estos se acompañan de trastornos fisiopatológicos de gran importancia en la clínica. No obstante que el mecanismo por el cual esto ocurre aún no se conoce del todo, se asume que los oxiesteroles alteran vías metabólicas, inducen la modificación de algunas proteínas e incrementan la cantidad de especies reactivas del oxígeno lo que provoca un desbalance del equilibrio antioxidante/ pro-oxidante en la célula dando lugar al estrés oxidativo. Recientemente este evento fisiológico se ha asociado con la enfermedad cardiovascular, en virtud de ser un suceso precoz de la disfunción del tejido que cubre a los vasos sanguíneos que nutren al corazón.

Es así como una de las patologías mejor descritas donde la participación de los oxiesteroles ha sido ampliamente analizada es la aterosclerosis. Esta caracterizada por la acumulación de depósitos de oxiesteroles en los macrófagos de las paredes de grandes vasos sanguíneos como la aorta, propiciando la formación de trombos que desencadenan un infarto cardiaco. Hasta el momento se sabe que el 20\% de los oxiesteroles identificados en la placa de ateroma, provienen de nuestra dieta, principalmente de alimentos de origen animal ricos en colesterol como el chicharrón, la machaca o los camarones.

Enfermedades neurodegenerativas, como el Alzheimer, y la enfermedad de Parkinson, constituyen otro conjunto de condiciones que a menudo están relacionados con oxisteroles. El cerebro representa sólo el 2\% del peso corporal de un individuo. Dado que está aislado por la barrera hematoencefálica, su colesterol tiene que ser sintetizado in situ, y su exceso se elimina después de su conversión a oxiesteroles por medios enzimáticos, que a diferencia del colesterol, éstos si pueden pasar fácilmente a través de la barrera hematoencefálica para ser metabolizados en el hígado. En este contexto, no es de sorprender que los oxiesteroles juegan un papel activo en condiciones patológicas relacionadas con la desregulación de la homeostasis del colesterol cerebral.

Entre las posibles causas que generan la enfermedad de Alzheimer- que es la forma de demencia mas común, que afecta a millones de personas- se encontró que un defecto en el proceso enzimático de la conversión del colesterol a oxiesteroles está implicado en la alteración del metabolismo del colesterol, la modulación de la neuroinflamación, además de propiciarse la formación de las placas seniles, que son agregados protéicos que no favorecen la correcta interacción entre las neuronas y por consiguiente se promueve su muerte; por lo que, los pacientes con este padecimiento manifiestan ausencia de la memoria.

La enfermedad de Parkinson es el trastor- 
no del movimiento más común. Se caracteriza por la pérdida de funcionalidad de las neuronas dopaminérgicas cuya función es esencial en procesos biológicos como el movimiento, la motivación y la función intelectual. Ciertos oxiesteroles, como el 27-hidroxicolesterol, es particularmente responsable de causar la destrucción de las neuronas que contienen dopamina y favorecer la formación de agregados de una proteína llamada a-sinucleina. A pesar de lo anterior, algunos informes clínicos prospectivos han proporcionado una negativa o nula correlación entre la enfermedad de Parkinson y los oxisteroles. Sin embargo, curiosamente, existe una superposición entre la enfermedad de Parkinson y el Alzheimer; a saber, una subpoblación de pacientes con enfermedad de Parkinson también exhiben la formación de las placas seniles, y los pacientes con Alzheimer presentan agregados de a-sinucleina. Recientemente se ha postulado que es éste oxiesterol, el 27-hidroxicolesterol, el agente causal de la superposición, ya que aumenta la producción de las palcas seniles, la acumulación de la proteína a-sinucleina, y el estrés oxidativo, que son características en ambos padecimientos.

Los oxiesteroles también están asociados con otro tipo de padecimiento como el cáncer3 de piel, pulmón, glándula mamaria y próstata. Pueden ejercen su efecto en las tres etapas de la carcinogénesis: dañando el ADN, induciendo la expresión de prostaglandinas del tipo de las cicloxigenasas o bien por la estimulación de la migración de células tumorales.

A manera de conclusión, los oxisteroles son importantes derivados oxigenados del colesterol. Las últimas tres décadas de investigación no sólo han puesto de manifiesto que los oxiesteroles son moléculas potencialmente dañinas si se acumulan en condiciones fisiopatológicas, sino también se descubrió su importancia en funciones fisiológicas como ser productos intermedios del metabolismo, moduladores de la permeabilidad celular, reguladores de la homeostasis del colesterol y de la expresión génica, y receptores en la señalización celular. El progreso en el esclarecimiento del papel de las interacciones entre los oxiesteroles con receptores en células humanas (por ejemplo, los receptores de estrógenos, modificaciones protéicas en la Enfermedad de Niemann-Pick o proteínas que controlan el intercambio celular del colesterol conocidas como OSBP) ha abierto nuevas vías para una mejor comprensión del metabolismo de los lípidos, enfermedad de Alzheimer, y otras condiciones patológicas humanas. El mundo de los oxisteroles es un campo amplio que todavía requiere un gran trabajo de investigación. Mediante el desarrollo de la metodología analítica y en la manipulación genética in vivo, así como los modelos detallados de las simulaciones por ordenadores, se podrá comprender cómo estos derivados oxidados del colesterol gobiernan la señalización celular, modulan la expresión génica, e influyen en nuestra salud o enfermedad.

\section{Figura 1. Estructura química del colesterol}

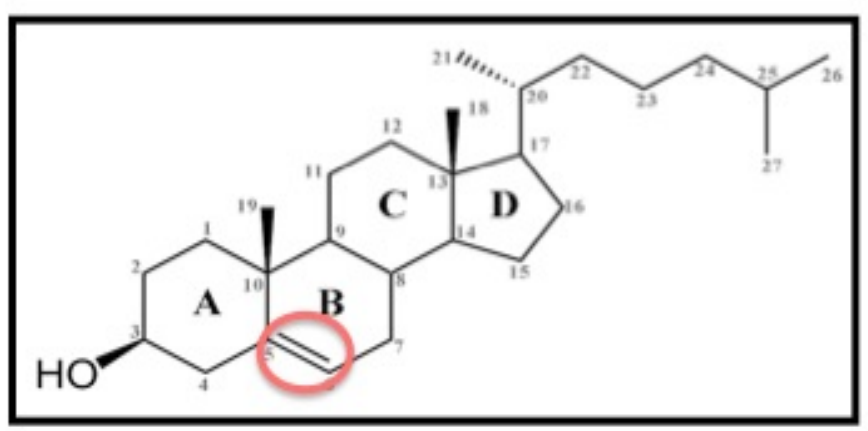

Figura 2. Estructura química de los oxiesteroles

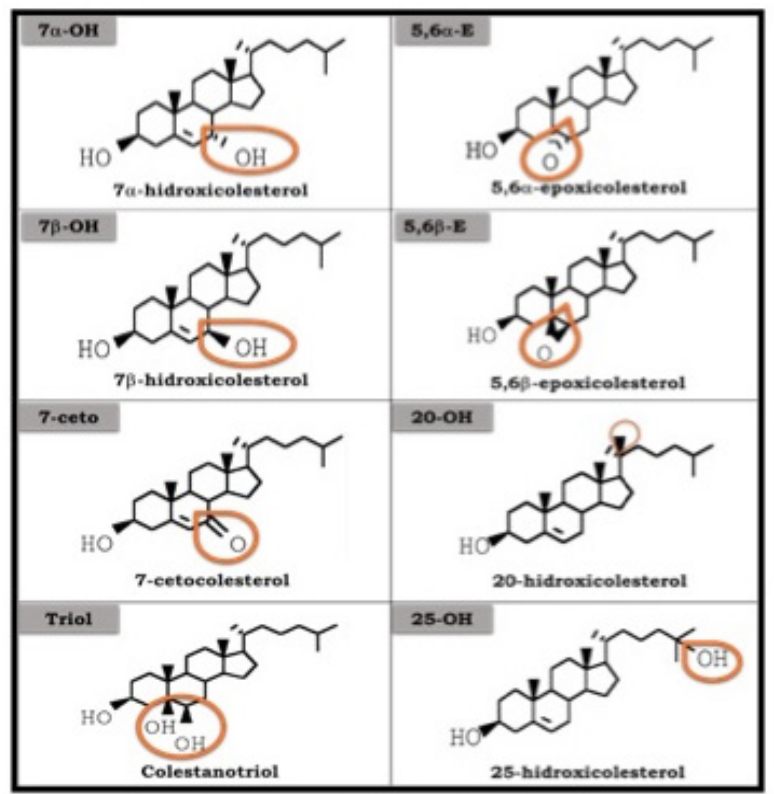

